\title{
Application of a Mix of Vegetables Residues as Inhibitor for Carbon Steel
}

\author{
L.S. Barreto ${ }^{a, b}$, A.M. Santos ${ }^{b, c}$, T.F. de Almeida ${ }^{b, d}$, D. R. Silva ${ }^{b}$, F. Cotting ${ }^{a}$ (), V.R. Capelossi ${ }^{b *}$ (]) \\ ${ }^{a}$ Universidade Federal de Pernambuco, Centro de Ciências Exatas e Naturais, Recife, PE, Brasil. \\ ${ }^{b}$ Universidade Estadual de Santa Cruz, Departamento de Ciência e Tecnologia, Programa de \\ Pós-Graduação em Ciência, Inovação e Modelagem em Materiais, Ilhéus, BA, Brasil. \\ ${ }^{c}$ Universidade Federal do Recôncavo Baiano, Centro de Ciência e Tecnologia em Energia e \\ Sustentabilidade, Feira de Santana, BA, Brasil. \\ ${ }^{d}$ Escola Politécnica da Universidade de São Paulo, Departamento de Engenharia Metalúrgica e de \\ Materiais, São Paulo, SP, Brasil. \\ ${ }^{e}$ Universidade Federal de Minas Gerais, Departamento de Engenharia Química, Belo Horizonte, MG, \\ Brasil.
}

Received: September 23, 2020; Revised: July 21, 2021; Accepted: September 23, 2021

This work investigates the synergistic use of Theobroma cacao (Cocoa), and Elaeis guineensis (Palm oil) as corrosion inhibitors for carbon steel in 0.5 mol.L-1 hydrochloric acid solution, in the absence and presence of different mixture concentrations of the studied compounds. The efficiency of corrosion inhibitors was studied by gravimetric tests and the corrosion resistance by electrochemical tests, such as electrochemical impedance spectroscopy (EIS) and polarization curves. The chemical composition of the cocoa bark powder and palm kernel cake powder was evaluated by Fourier transform infrared spectroscopy (FTIR). The results of the gravimetric tests showed an inhibition efficiency of $79 \%$ for the cocoa bark powder and $76 \%$ for palm kernel cake powder, however, the mixture of the compounds presented an inhibition superior to $94 \%$, showing the great synergism between the studied species. These results corroborate the values obtained from EIS.

Keywords: Corrosion, inhibitors, EIS, FTIR, Gravimetric tests, Cocoa and palm oil.

\section{Introduction}

The corrosion in metallic surfaces has become a relevant problem for society, which represents a big material and economic waste, falling upon a relevant phenomenon that affects the chemical, petrochemical, naval, civil construction, automotive, aerospace, white line, and communication sectors, among others, causing environmental and economic impacts ${ }^{1}$. The study by the National Association of Corrosion Engineers (NACE) estimated that the global cost of corrosion was US $\$ 2.5$ trillion per year, which is equivalent to $3.4 \%$ of the global Gross Domestic Product (GDP) ${ }^{2}$.

The cost is an important aspect of the fight against corrosive processes, and with the advancement of technology, the demand for corrosion-resistant products is significant. Coatings and corrosion inhibitors are used to minimize the effects of corrosion. Some synthetic corrosion inhibitors have toxic properties that are harmful to the environment and human health. In this context, the use of natural inhibitors is beneficial both financially and environmentally, due to their biodegradability, ecological acceptance, and renewability ${ }^{3}$

This includes, for example, Boswellia serrata ${ }^{4}$, Theobrama cacao ${ }^{5}$, Glycyrrhuza glabra ${ }^{6}$, and some vegetables, such as the garlic peel ${ }^{7}$, Xanthium strumarion ${ }^{8}$, castor bark ${ }^{9}$ Cotton Seed ${ }^{10}$, Spilanthes acmella Leaves ${ }^{11}$, widely distributed and low economic value, including byproducts of agro-industrial processes and agricultural waste ${ }^{12}$.

*e-mail: vera.rosa@gmail.com
A notable feature in these works is related to the wide variety of chemical compounds in these vegetables, mainly polyphenols, which are efficient corrosion inhibitors for metals ${ }^{13}$. The corrosion inhibition efficiency from the byproducts of vegetables is normally linked to the presence of organic species such as tannins, alkaloids, nitrogenous bases, carbohydrates, and proteins in their compositions ${ }^{6-14-15}$.

Some studies about the cocoa bark have revealed the presence of a series of interesting compounds, such as catechins, epicatechins, procyanidins, and methylxanthines, caffeine (1,3,7-trimethylxanthin), theophylline (1,3-dimethylxanthin), and theobromine (3,7-dimethylxanthine), and some of these studies reveal the antioxidant activity of cocoa bark ${ }^{16-17-18-19-20}$.

The studies of Fayomi and Popoola (2014) ${ }^{21}$ and Nwigbo et al., (2012) ${ }^{22}$ revealed that palm oil has good inhibitory properties, containing oxygen, nitrogen, and aromatic rings in its composition ${ }^{21}$, which justifies that palm kernel cake can present inhibitory properties since it has fractions of the oil that was not extracted ${ }^{23}$, which is a theory confirmed by SANTOS et al. (2020), that reported an inhibitory efficiency of $87 \%$ for palm kernel cake ${ }^{24}$.

Taking into account the interest in preserving carbon steel, the present work focuses on investigating the synergistic use of natural residues from cocoa bark and palm kernel cake as corrosion inhibitors for carbon steel in 0.5 mol. $\mathrm{L}^{-1}$ hydrochloric acid solution. 


\section{Methodology}

The metal used in the corrosion resistance evaluation was the ASTM 1020 carbon steel. It is the most utilized steel with carbon content below $2 \%$, which is considered a material of high added value, used in several sectors, due to its wide applicability and also for having advantageous mechanical properties for engineering applications ${ }^{25}$. Its chemical composition (\%) is formed by: $\mathrm{C}=0.17$; $\mathrm{Mn}$ $=0.30 ; \mathrm{P}=0.04 ; \mathrm{S}=0.05$ e $\mathrm{Fe}=0.44^{26}$. The 1020 carbon steel samples were used in dimensions of $20 \times 20 \times 8 \mathrm{~mm}$. The surface of each specimen was progressively treated with sandpaper of grades $80,120,320,400,600$ e 1200 . Then, they were washed with distilled water, ethanol and acetone, and finally dried with a hot air stream.

The cocoa bark and palm kernel cake were initially washed in water and dried in an oven at $70^{\circ} \mathrm{C}$ for $24 \mathrm{~h}$. Subsequently, to reduce the particle size, the material was conducted to a knife mill with a single rotation speed. Next, the grinding product was separated with a sieves system using an electromagnetic stirrer for $15 \mathrm{~min}$. The particle size of 170 mesh was separated and named as cocoa bark powder (CBP) and palm kernel cake powder (PKCP). Preliminary tests were carried out with five different concentrations for both materials (Table 1).

The analyses of FTIR (Thermo Scientific Nicolet iS10) were obtained in the range of 4000 to $400 \mathrm{~cm}^{-1}$, at a resolution of $4 \mathrm{~cm}^{-1}$. The samples were prepared using $\mathrm{KBr}$ pellets.

Electrochemical tests were carried out in triplicate with a potentiostat/galvanostat Metrohm Autolab, PGSTAT302N, with an impedance module and controlled by NOVA 1.11 software. Microcal ${ }^{\circledR}$ Origin $^{\circledR} 8.0$ software was used to process the data. A three-electrode electrochemical cell was used with $\mathrm{Ag}|\mathrm{AgCl}| \mathrm{KClsat}$ as the reference electrode, Rh-coated Ti wire with $1.6 \mathrm{~mm}$ diameter and $10 \mathrm{~cm}$ height as the counter electrode, carbon steel ASTM 1020 was employed as the working electrode with an exposed surface area of $1 \mathrm{~cm}^{2}$. The electrolyte was a $0.5 \mathrm{~mol} . \mathrm{L}^{-1} \mathrm{HCl}$ aqueous solution with different inhibitor concentrations.

Electrochemical experiments were carried out in the following sequence: Initially, the open circuit potential (OCP) was registered for $5400 \mathrm{~s}$; next, EIS measurements were performed, and finally, potentiodynamic polarization curves were obtained $120 \mathrm{~s}$ after completion of EIS tests. The EIS data were fitted using ZView2 software.

EIS experiments were carried out at the OCP in the frequency range from $100 \mathrm{kHz}$ to $10 \mathrm{mHz}$ with 10 points per decade using a perturbation amplitude of $10 \mathrm{mV}$. Anodic $(-30 \mathrm{mV}$ vs OCP to $+250 \mathrm{mV}$ vs OCP) and cathodic (+ $30 \mathrm{mV}$ vs OCP to $-250 \mathrm{mV}$ vs $\mathrm{OCP}$ ) polarization curves

Table 1. Inhibitor concentrations.

\begin{tabular}{cc}
\hline Inhibitor & Concentration $(\mathrm{g} / \mathrm{L})$ \\
\hline Blank & - \\
\hline CBP & 1.11 \\
\hline PKCP & 1.11 \\
\hline CBP + PKCP & $0.78 \mathrm{PKCP}+0.33 \mathrm{CBP}$ \\
\hline $\mathrm{CBP}+$ PKCP & $0.33 \mathrm{PKCP}+0.78 \mathrm{CBP}$ \\
\hline $\mathrm{CBP}+\mathrm{PKCP}$ & $1.11 \mathrm{PKCP}+1.11 \mathrm{CBP}$ \\
\hline
\end{tabular}

were obtained with different working electrodes, both at a scan rate of $0.5 \mathrm{mV} / \mathrm{s}$.

Gravimetric tests were performed in triplicate according to ASTM G1. The ASTM 1020 carbon steel samples were previously treated and cleaned before weighing on an analytical balance with an accuracy of $0.1 \mathrm{mg}$, to finally be immersed in a 0.5 mol. $\mathrm{L}^{-1} \mathrm{HCl}$ solution without and with different inhibitor concentrations. The immersion time was $2 \mathrm{~h}$.

For the weight loss measurement, the samples were removed from the solution after this interval, washed with distilled water, alcohol, acetone, and dried under a hot air stream.

The micrographs of the surfaces of the samples after $2 \mathrm{~h}$ of immersion in the test electrolyte in the absence and the presence of inhibitors were generated by a scanning electron microscopy (SEM) Quanta 250F after weight loss measurements.

\section{Results and Discussion}

\subsection{Fourier transform infrared spectroscopy (FTIR)}

Figures 1 and 2 show the FTIR spectra of CBP and $\mathrm{PKCP}$, respectively.

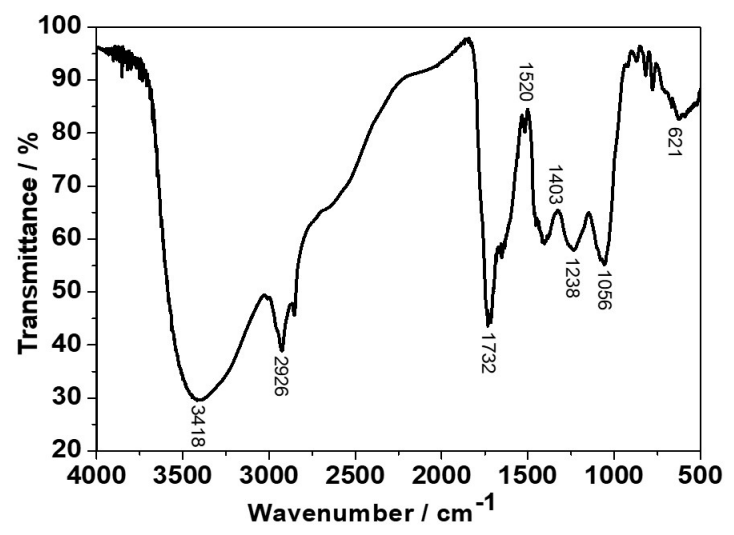

Figure 1. FTIR spectrum of CBP.

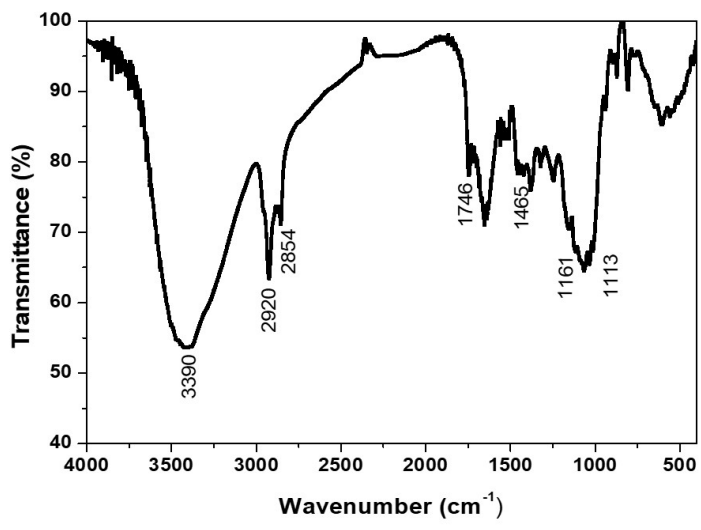

Figure 2. FTIR spectrum of PKCP. 
The spectra found are similar to each other, where the main bands were found in both 3418 of the studied inhibitors. CBP spectrum (Figure 1) has a strong absorption band at $\mathrm{cm}^{-1}$, and a similar spectrum was found in PKCP at $3390 \mathrm{~cm}^{-1}$ (Figure 2), which can be associated with the presence of $\mathrm{N}-\mathrm{H}$ and $\mathrm{OH}$ groups. Carboxylic acids, phenols, and amines may be present in the studied inhibitors, so these functional groups form complexes with hydrogen $(\mathrm{H}+)$, present on the metals surface, which cause blocking of anodes that are generated on the metal surface in contact with electrolytes, and thus, it retards the dissolution of the metal ${ }^{27-28-29}$.

Specific bands attributed to nitrogen-containing compounds were detected at $1520 \mathrm{~cm}^{-1}(\mathrm{C}=\mathrm{N})$ and $621 \mathrm{~cm}^{-1} \mathrm{NH}_{3}$ in the CBP spectrum. According to Zucchi (1985) ${ }^{31}$, organic compounds containing nitrogen can act as corrosion inhibitors due to their antioxidant properties, presenting ease on the formation of $\sigma$ bond between the inhibitor and the metal since they have high negative charges in the nitrogen atom ${ }^{31}$. Electron-donor functional groups further assist in this process. The band at $2900 \mathrm{~cm}^{-1}$ found in both inhibitors is related to aliphatic $\mathrm{C}-\mathrm{H}$ stretching vibrations, present in fatty acids (saturated and unsaturated) and carotenes ${ }^{32}$.

The band at $1730 \mathrm{~cm}^{-1}$ comes from the carbonyl group $(\mathrm{C}=\mathrm{O})$, present in fatty acids such as palmitic acid and oleic acid $^{33-34-35}$, as well as possible flavonoids and tannins.

The band at $1465 \mathrm{~cm}^{-1}$ is characterized by the vibration of $\mathrm{C}=\mathrm{C}$ double bonds present in aromatic rings ${ }^{22-36}$. At $1161 \mathrm{~cm}^{-1}$ there is another peak that can be attributed to the vibrations of aromatic rings, which according to Santos (2017) ${ }^{9}$, they come from phenolic groups (tocopherols, flavonoids, and tannins), which are adsorbed on the metallic surface to form a planar layer, resulting from the interaction of $\pi$ electrons of the molecule with the metal ${ }^{37}$.

The chemical characterization of CBP and PKCP obtained by FTIR (Figures 1 and 2) revealed the presence of aromatic rings and functional groups containing nitrogen, oxygen, and carbon in their structures, as well as electronegative functional groups, which explains their antioxidant and inhibitory properties ${ }^{38-39}$. The inhibitory action of these organic compounds can be attributed to their interactions with the metal surface through an adsorption process ${ }^{24-40}$. The generated film can act as a barrier between the metal and the electrolyte, so the inhibition efficiency can be related to the chemical characteristics of the adsorbed layer ${ }^{41}$.

\subsection{Electrochemical Impedance Spectroscopy (EIS)}

The EIS diagrams for ASTM 1020 carbon steel after 5400 seconds of immersion in the test electrolyte, with and without the inhibitors, are shown in Figures 3-5. Analysis of Nyquist plots shows the occurrence of a single flattened capacitive arc, whose diameter is always greater in the presence of inhibitors in comparison to the control system, indicating a decrease in corrosive activity at the interface. The maintenance of the aspect of the diagrams when the inhibitors were added to the solution suggests that the compounds only delay the corrosive process, without modifying its mechanism. Similar behavior has been observed in other studies in the literature ${ }^{5-24}$. The synergism of CBP and PKCP in the highest studied concentration with $1.11 \mathrm{~g} / \mathrm{L}$ of each component, presented the highest impedance value,

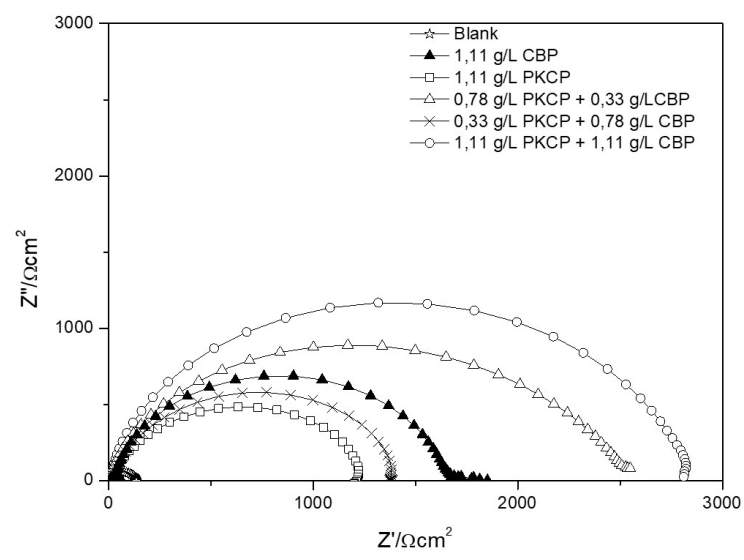

Figure 3. Nyquist diagrams of ASTM 1020 carbon steel in a 0.5 mol. $\mathrm{L}^{-1} \mathrm{HCl}$ solution with various $\mathrm{CBP}$ and $\mathrm{PKCP}$ concentrations.

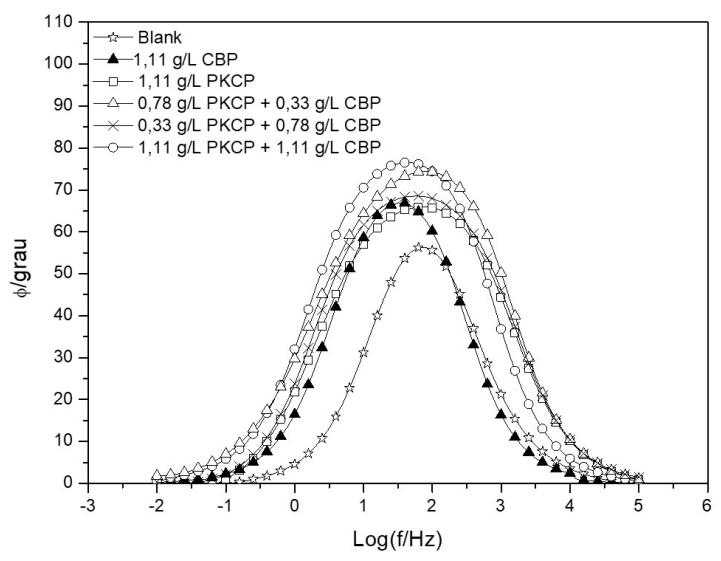

Figure 4. Bode phase angle plots for ASTM 1020 carbon steel in a 0.5 mol. $\mathrm{L}^{-1} \mathrm{HCl}$ solution with various $\mathrm{CBP}$ and PKCP concentrations.

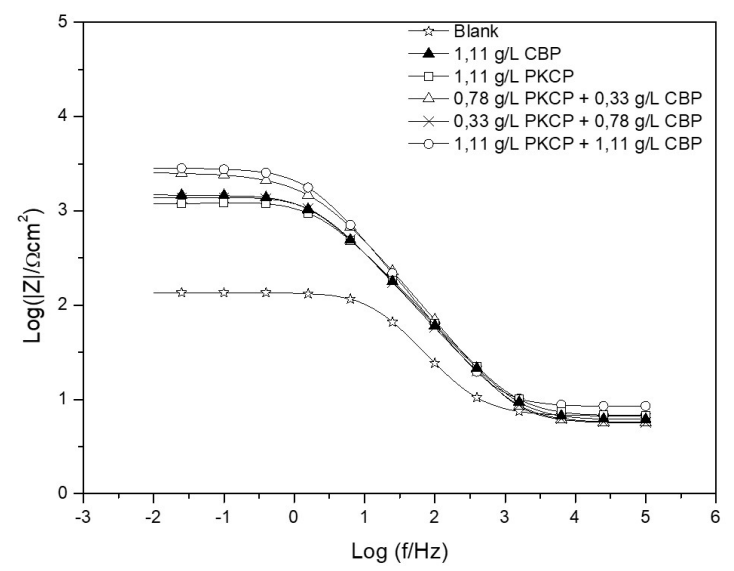

Figure 5. Bode impedance modulus plots for ASTM 1020 carbon steel in a 0.5 mol. $\mathrm{L}^{-1} \mathrm{HCl}$ solution with various $\mathrm{CBP}$ and $\mathrm{PKCP}$ concentrations. 
which can lead to the comprehension that they both work simultaneously to reduce the corrosive process.

It can be observed that in the presence of any inhibitor concentration, in comparison to the control system, the presented time constant results in phase angle values in a wider frequency range, indicating a deceleration in the reactions involved. Furthermore, the increasing values of phase angle suggest the adsorption of the studied compounds on the working electrode by increasing the capacitive effect of the electrochemical system ${ }^{42-43}$.

The impedance modulus diagrams show only a single time constant in all curves, which indicates that the inhibitors act by forming a protective layer that is adsorbed on the substrate surface $^{44}$. The highest values of phase angle and impedance modulus were obtained when 1.11 g.L $\mathrm{L}^{-1}$ of CBK and PKCP were added in the test electrolyte, which corresponds to a lower corrosion intensity.

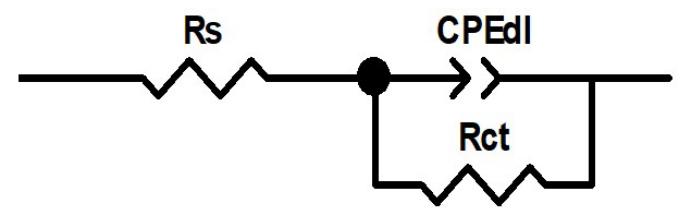

Figure 6. Equivalent circuit used to fit the EIS data.
For a better quantitative analysis of the general impedance behavior, the EIS diagrams in Figure 5 were fitted using an electric equivalent circuit (Figure 6) generally employed to model the impedance response of steel in acidic solutions with or without inhibitors ${ }^{45-47}$.

In search of a more precise adjustment, the phase constant element was inserted instead of a pure double layer electric capacitor, thus compensating for deviations from the ideal behavior. This equivalent circuit model, shown in Figure 6, is widely used in studies of natural inhibitors in the literature ${ }^{5,9,32-34}$. The impedance data adjustment for the 1.11 g.L-1 PKCP + 1.11 g.L-1 CBP concentration of green inhibitor on the Z-View software simulation interface can be seen in Figure 7.

The mathematical procedure was performed with software Zview 2.4. The fitted parameters and the inhibition efficiency are shown in Table 2.

The charge transfers resistance $(R \mathrm{tc})$ was calculated from the difference between the highest and lowest frequencies obtained in impedance. The double layer capacitance $\left(C P E_{\mathrm{dl}}\right)$ was calculated using Equation 1:

$$
C P E_{d l}=1 /(2 \pi \cdot f \max \cdot R \mathrm{ct})
$$

Results in Table 2 clearly show that $R$ ct values increased in the presence of inhibitors while $C P E_{\mathrm{dl}}$ values decreased, showing that the utilized compounds act in the electric double layer to reduce the corrosion rate of carbon steel.

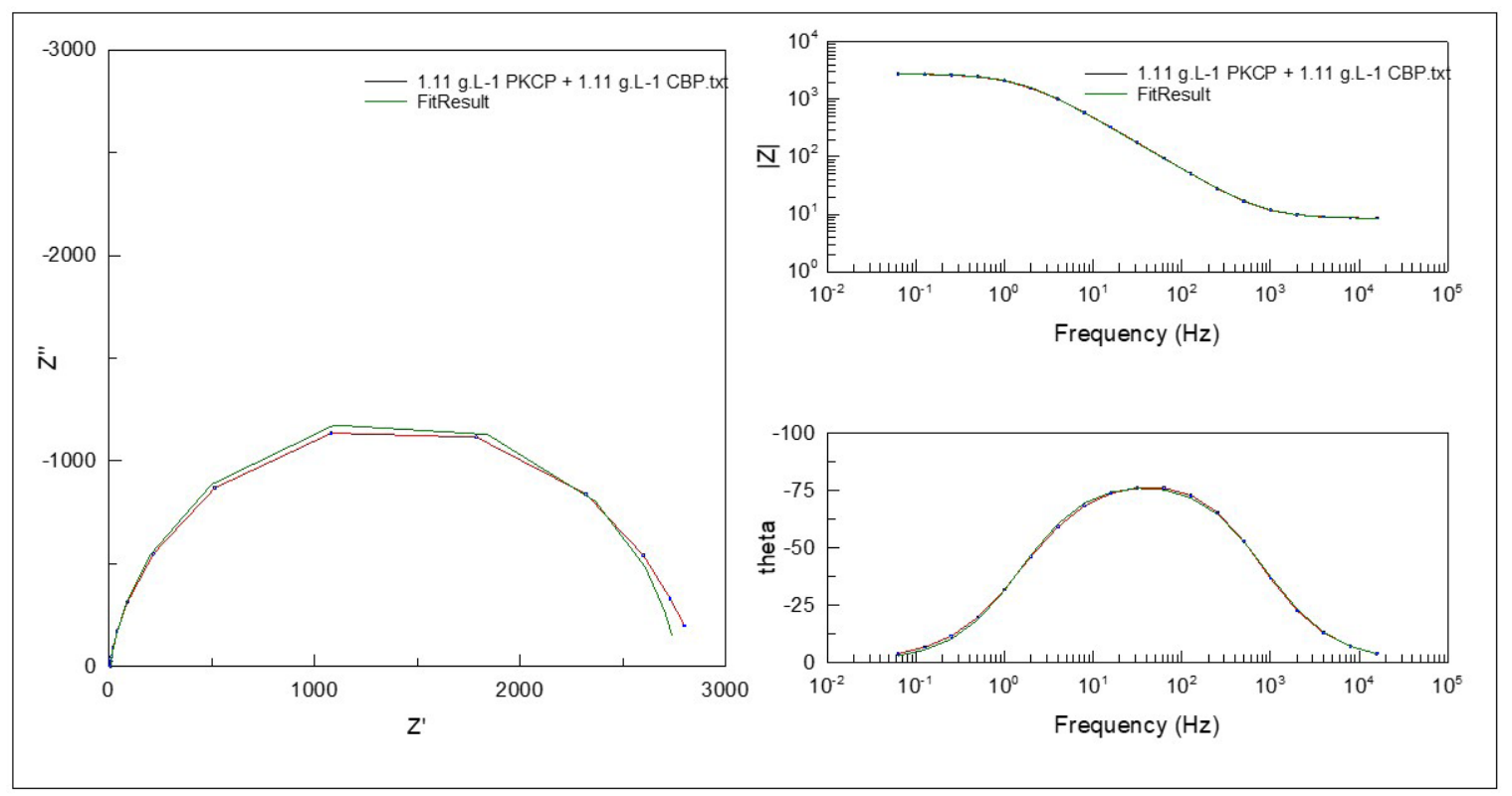

Figure 7.Z-View software interface for the adjustment of electrochemical impedance data (in the presence of 1.11 g.L $\mathrm{L}^{-1} \mathrm{PKCP}+1.11$ g.L $\mathrm{L}^{-1} \mathrm{CBP}$ of inhibitor) to the equivalent electrical circuit.

Table 2. Parameters from the fitting EIS diagrams with the equivalent circuit of Figure 6.

\begin{tabular}{lccccccc}
\hline $\begin{array}{c}\text { Concentration } \\
\left(\mathrm{g} . \mathrm{L}^{-1}\right)\end{array}$ & $\begin{array}{c}R_{\mathrm{s}} \\
\left(\Omega . \mathrm{cm}^{2}\right)\end{array}$ & $\begin{array}{c}R_{\mathrm{ct}} \\
\left(\Omega . \mathrm{cm}^{2}\right)\end{array}$ & $\begin{array}{c}\text { Error } \\
(\%)\end{array}$ & $\begin{array}{c}C P E_{\mathrm{dl}} \\
\left(\mu \mathrm{Fcm} \mathrm{s}^{(\mathrm{n}-1)}\right)\end{array}$ & $\mathrm{n}$ & $\begin{array}{c}\chi^{2} \\
(\%)\end{array}$ \\
\hline Blank & 10.78 & 219 & 0.22 & $2.11 \times 10^{-4}$ & 0.84 & $2.97 \times 10^{-3}$ & - \\
\hline $1.11 \mathrm{~g} / \mathrm{L}$ CBP & 9.23 & 1395 & 0.60 & $5.95 \times 10^{-5}$ & 0.83 & $1.85 \times 10^{-3}$ & 84.3 \\
\hline $1.11 \mathrm{~g} / \mathrm{L}$ PKCP & 9.95 & 1227 & 0.42 & $6.90 \times 10^{-5}$ & 0.82 & $2.05 \times 10^{-3}$ & 82.1 \\
\hline $1.11 \mathrm{~g} / \mathrm{L}$ PKCP $+1.11 \mathrm{~g} / \mathrm{L} \mathrm{CBP}$ & 8.43 & 2758 & 0.72 & $4.58 \times 10^{-5}$ & 0.91 & $9.62 \times 10^{-4}$ & 92.1 \\
\hline
\end{tabular}


The corrosion inhibition efficiencies $(\eta)$ were calculated using Equation 2:

$\eta=\left(R_{\text {Tinb }}-R_{\text {Tco }}\right) / R_{\text {Tinb }} \times 100$

where $R_{\text {Tinb }}$ and $R_{\text {Tco }}$ are the charge transfer resistance in the presence and the absence of inhibitor, respectively.

The inhibition efficiency calculated from the Rct values with and without the presence of inhibitors was $84.3 \%$ for CBP, $82.1 \%$ for PKCP, and $92.1 \%$ for the synergism of $\mathrm{CBP}$ and PKCP.

\subsection{Potentiodynamic polarization curves}

Figures 8 and 9 show the potentiodynamic polarization curves obtained after $110 \mathrm{~min}$ of immersion in a $0.5 \mathrm{~mol} . \mathrm{L}^{-1} \mathrm{HCl}$ solution with and without the presence of the studied inhibitors.

For anodic curves, it can be observed in Figure 6 that the corrosion potential for samples with inhibitors shifts to higher values in comparison to the sample without inhibitor. The anodic current densities are lower for samples with the inhibitors in comparison to the control system (Figure 8), revealing the anodic behavior of the inhibitors. Differently, the cathodic current densities (Figure 9) of the samples with inhibitors are lower than the one represented as blank. The results corroborated the literature $5,24,48$, demonstrating that in the presence of the studied inhibitors, the response of an anodic inhibitor prevailed. It was verified that there was no change in the shape of the polarization curves in the presence of inhibitors, which were only shifted to lower current density values, corroborating the interpretation of the EIS diagrams, in the sense that the inhibitory action acts in the electric double layer of the electrochemical system.

\subsection{Gravimetric tests}

The results of gravimetric tests are shown in Table 3. The inhibition efficiency $(\eta)$ was calculated using Equation 3 , where $C_{\mathrm{Ro}}$ represents the corrosion rate in the absence of inhibitor, and $C_{\mathrm{Ri}}$ is the corrosion rate in the presence of inhibitor ${ }^{49}$.

$\eta=\left(1-C_{\mathrm{Ri}} / C_{\mathrm{Ro}}\right) \times 100$

As it was seen in the electrochemical results, Table 3 shows that the addition of CBP and PKCP to the electrolyte enhances the inhibition efficiency, confirming that these two substances act as corrosion inhibitors for ASTM 1020 carbon steel in $0.5 \mathrm{~mol} . \mathrm{L}^{-1} \mathrm{HCl}$ solution. This process probably occurs due to the adsorption of molecules with inhibitory properties on the surface of the working electrode, as suggested by the EIS results ${ }^{50}$.

The highest efficiency value obtained was $94 \%$ for the concentration of $1.11 \mathrm{~g} . \mathrm{L}^{-1}$ of CBP and PKCP, which is higher than the $70 \%$ indicated in the literature as a parameter of an efficient inhibitor ${ }^{51}$, which corroborates the electrochemical tests and the results from literature ${ }^{52-56}$. It also confirms the synergism of the two substances to increase the efficiency of the system against corrosion.

\subsection{SEM characterization}

Surface images of the steel were obtained by SEM after gravimetric tests $\left(120 \mathrm{~min}\right.$ of immersion in $0.5 \mathrm{~mol} . \mathrm{L}^{-1} \mathrm{HCl}$ solution) in the presence and absence of CBP, PKCP, and the synergism of CBP with PKCP (Figure 10).

When comparing the four images, it can be noticed that there was widespread corrosion in the absence of the inhibitors (Figure 9a), whereas when the inhibitors were added to the test electrolyte, the corrosive process was reduced and the surface was less damaged (Figure $9 \mathrm{~b}$ and $9 \mathrm{c}$ ). Finally, the image of the sample exposed to the solution containing the synergism of CBP and PKCP (Figure 9d), shows the smoothest surface, indicating that the protection against corrosion generated by these inhibitors is not based on precipitation of a layer of corrosive product, but in an adsorption process.

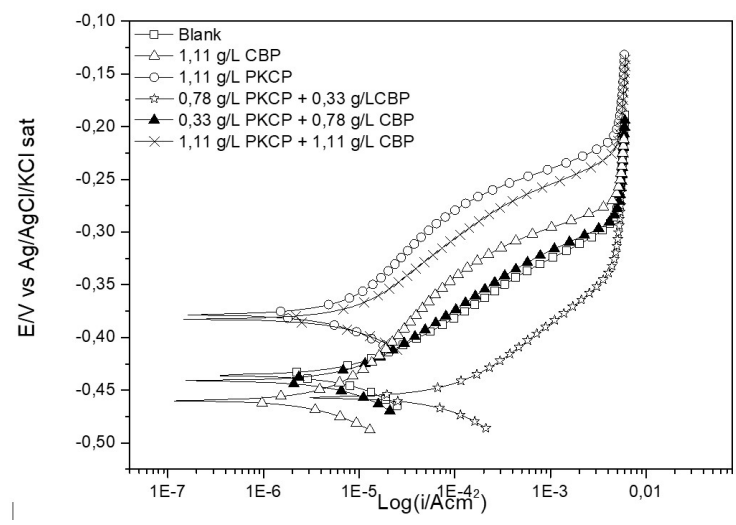

Figure 8. Anodic polarization curves obtained for the ASTM 1020 carbon steel in a 0,5 mol. $\mathrm{L}^{-1} \mathrm{HCl}$ solution with various $\mathrm{CBP}$ and PKCP concentrations.

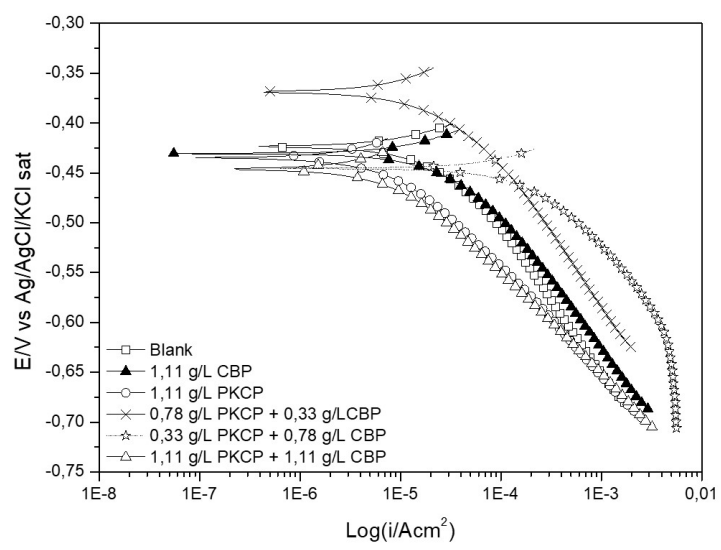

Figure 9. Cathodic polarization curves obtained for the ASTM 1020 carbon steel in a 0.5 mol. $\mathrm{L}^{-1} \mathrm{HCl}$ solution with various $\mathrm{CBP}$ and PKCP concentrations.

Table 3. Gravimetric results of ASTM 1020 carbon steel after 120 min of immersion in a 0,5 mol. $\mathrm{L}^{-1} \mathrm{HCl}$ solution without and with different inhibitor concentrations.

\begin{tabular}{cc}
\hline Concentration & Efficiency \\
\hline Blank & - \\
\hline $1.11 \mathrm{~g} / \mathrm{L} \mathrm{CBP}$ & $79 \%$ \\
\hline $1.11 \mathrm{~g} / \mathrm{L} \mathrm{PKCP}$ & $76 \%$ \\
\hline $1.11 \mathrm{~g} / \mathrm{L} \mathrm{PKCP}+1.11 \mathrm{~g} / \mathrm{L} \mathrm{CBP}$ & $94 \%$ \\
\hline
\end{tabular}



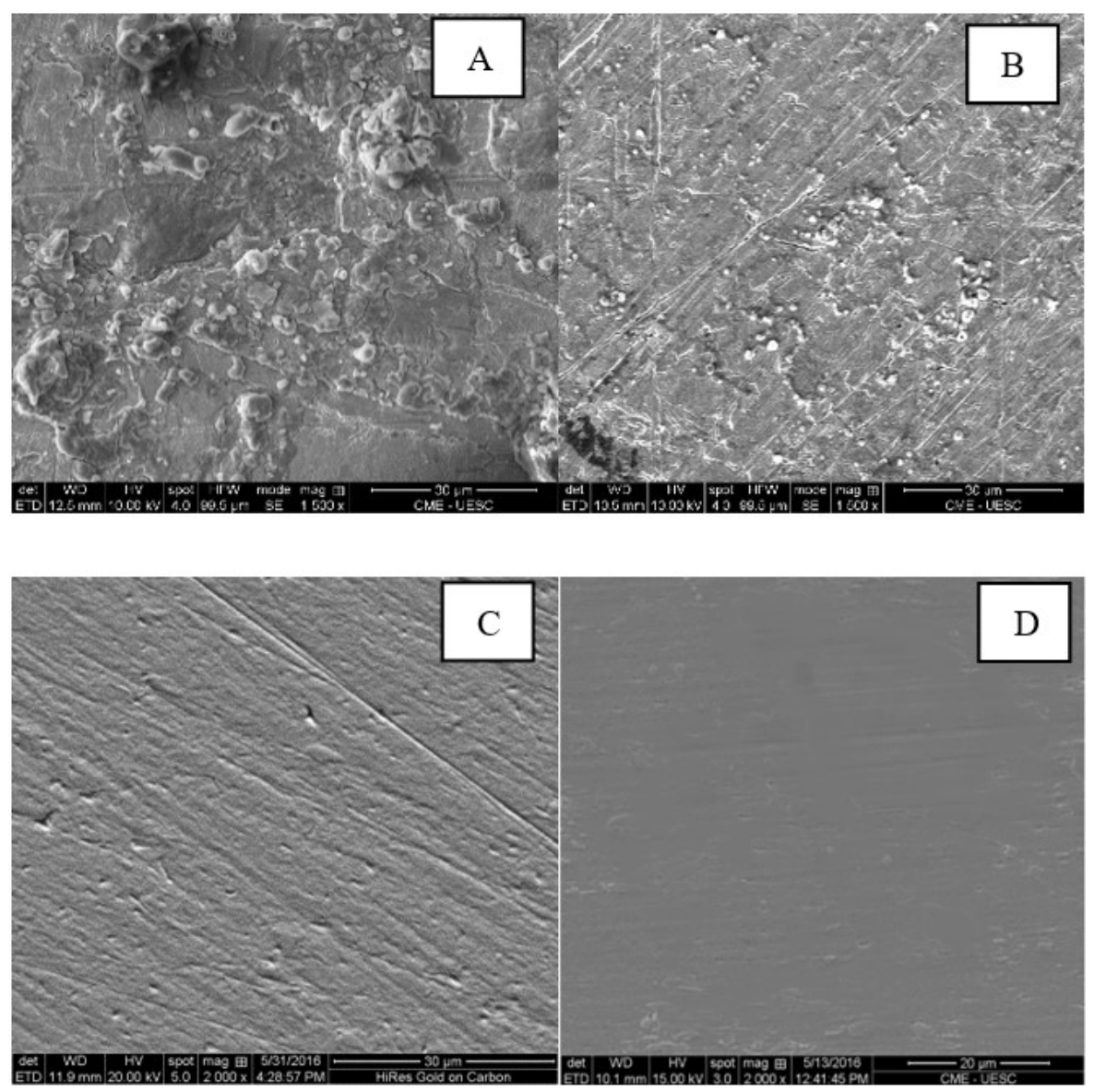

Figure 10. SEM images of ASTM 1020 carbon steel after $120 \mathrm{~min}$ of immersion in 0.5 mol. $\mathrm{L}^{-1} \mathrm{HCl}$ solution in the absence (a) and the presence of CBP (b), PKCP (c), and the synergism of CBP and PKCP (d).

\subsection{Economic analysis}

The costs of market values for the main synthetic inhibitors with their respective companies of reselling or manufacturing are presented below (Table 4):

These corrosion inhibitors are synthetic chemicals, characterized by high manufacturing costs, and great toxicity associated with risks to human health. Therefore, the study of natural corrosion inhibitors is prominent, mainly due to their sustainable profile, low cost, and high suitability.

Barreto et al. (2018) ${ }^{5}$ studied the use of cocoa bark extract for possible substitution of benzotriazole (BTAH) in the inhibition of 1020 carbon steel in hydrochloric acid. The inhibition efficiency calculations from weight loss, EIS, and polarization tests have shown that cocoa bark extract is only slightly less efficient than the BTAH to mitigate the corrosion in the aforementioned conditions ${ }^{5}$.

In the cocoa productive chain, the fruit is not fully utilized, generating large amounts of waste, which estimations indicate the disposal of $80 \%$. Most of the cocoa barks are left in the plantations in the form of "casqueiros", which can provoke the degradation of the soil structure as a source of inoculum of pathogenic fungi toward the plants, harming the environment ${ }^{57}$.
Worldwide cocoa production for the 2018/2019 harvest is estimated to be approximately 4.834 thousand tons ${ }^{58}$. According to Mororó (2007) ${ }^{59}$, for the production of a ton of dried cocoa beans, 7 tons of bark are generated ${ }^{59}$.

Among the potentialities of cocoa bark consumption, the use in animal feed, boiler fuel, and fertilizers are the highlights ${ }^{60}$.

Palm oil (Elaeis Guineesis Jacq.) has a strong influence on the cuisine of the state of Bahia (Brazil), and also on the economic and environmental aspects. Its main products are the palm oil from the mesocarp and palm kernel, both extracted from the fruit ${ }^{61}$. Palm oil is widely used as vegetable oil and the forecast for world consumption in 2020 can reach 43 million tons, indicating that the production should increase along with the demand ${ }^{62}$.

Palm oil production results in some byproducts such as bunches, mesocarp fiber, nutshells that are used as solid fuels; the palm kernel cake that is used as animal feed; POME and solid sludge used as fertilizers and to feed the boiler ${ }^{61}$.

Bearing in mind how large the waste volume generated in the productive chain of cocoa and palm oil is, adding value to byproducts is important from a scientific, economic, and technological point of view. Therefore, it is necessary to develop a critical technical awareness that must be built within society and university, always searching for industrial 
routes that can predict environmental liabilities and turn them into clean technologies, that can be defined as the set of methods and techniques that aims to mitigate waste and has the environment preservation as its central axis. Thus, the use of cocoa bark and palm kernel cake meets these needs and this study proves that they are effective as natural corrosion inhibitors.

\section{Mechanism of Inhibition}

The electrolyte nature, the corrosion inhibitor composition, and the composition of surfaces are determinants in the adsorption of corrosion inhibitors on the metal substrates. The traditional inhibitors are organic compounds that contain heteroatoms such as oxygen, nitrogen, phosphorous, sulfur, and aromatic rings ${ }^{63}$. The natural corrosion inhibitors composition is very complex, and the compounds reported in these substances, which are responsible for the inhibitory effect, have similar characteristics to the traditional inhibitors, for example, tannins, alkaloids, carbohydrates, and proteins.
Through the free electrons of heteroatoms and $\pi$ electrons of multiple bonds, the inhibitory species can adsorb on the metallic surfaces by electrons donate, in the empty d-orbitals. In $\mathrm{HCl}$ electrolytes, the iron surface charges positively, and the chloride ions are attracted to the surface. Thus, the chloride ions act as a bridge between inhibitor molecules and metal surfaces due to the highly stabilized coordination inter-medium on the metal surface ${ }^{63-64}$. Besides, the inhibitory species can interact electrostatically with the metal surfaces, resulting in physical adsorption ${ }^{65}$.

In addition of the long-chain compounds, which are important to cover the metallic surface; both cocoa and the palm have antioxidant compounds, that are essential to the high inhibitors efficiency presented. Nevertheless, their antioxidants compounds are from different natures, which was verified by FTIR analysis for these inhibitors. While cocoa is rich in polyphenols, theobromine, and caffeine (Figure 11a); the palm is rich in A and E vitamins (Figure 11b). Thus, the inhibitive action of the studied

Table 4. Cost of market values for the main synthetic inhibitors.

\begin{tabular}{ccc}
\hline Inhibitor & Cost per kg & Company \\
\hline Zinc Phosphate PZ20 & $\$ 6.98$ & Adexim comexim \\
\hline Zinc Chromate (CZ 20) & $\$ 7.91$ & Adexim comexim \\
\hline Novinox PAT 15 & $\$ 13.85$ & Adexim comexim \\
\hline C.R.Z.-instant cold galvanizing & $\$ 79.6$ & QUIMATIC TAPMATIC \\
\hline Nonylphenol Ethoxylated 9,5 & $\$ 3.60$ & Macler \\
\hline Benzotriazole (BTAH) & $\$ 1.75$ & Sigma-Aldrich \\
\hline Palm Kernel Cake Powder (PKCP) & $\$ 0.25$ & Óleos de Palma S/A (Bahia, BR). \\
\hline Cocoa Bark Powder (CBP) & $\$ 0.25$ & UESC
\end{tabular}
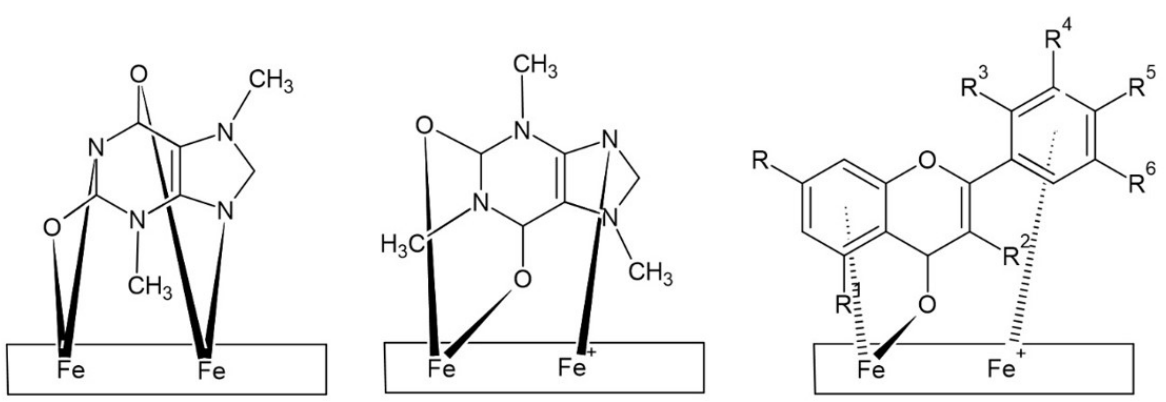

(a)
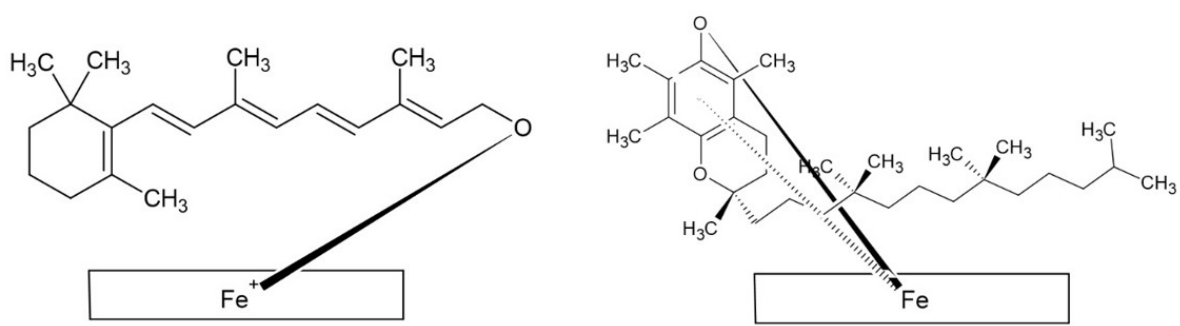

(b)

Figure 11. Skeletal representation of adsorption of Teobromina, Cafeina, Flavonoides (a), Vitamina A and Vitamina E (b) on the carbon steel ASTM 1020 surface. 
compounds could be attributed to the presence of the longchain molecules, responsible for blocking wide areas on the metallic surface thus inhibiting corrosion by covering wide areas on the carbon steel surface and by the adsorption of the antioxidant compounds, which containing $\mathrm{O}, \mathrm{N}$, and $\mathrm{S}$ atoms, $\pi$ electrons, and aromatic rings ${ }^{64}$.

\section{Conclusions}

Through the analysis of the results, it was possible to conclude that the $\mathrm{CBP}$ and $\mathrm{PKCP}$ both presented the required potential to be used as corrosion inhibitors for ASTM 1020 carbon steel in 0.5 mol. $\mathrm{L}^{-1} \mathrm{HCl}$ solution.

The spectra from the chemical analysis by FTIR indicate the presence of species that can be found in corrosion inhibitors, such as oxygen atoms, nitrogen, and aromatic ring groups that probably adsorb on the sample surface, which explains the inhibitory properties.

The electrochemical tests indicate that the corrosion mechanism is not altered in the presence of the studied inhibitors. And it was possible to suggest the anodic inhibitory action from the polarization curves.

Gravimetric tests showed that in the presence of CBP, the inhibition efficiency is approximately $79 \%$, while for the PKCP was $76 \%$. Concerning synergism, the results demonstrate an increase in the corrosion resistance efficiency, reaching values of $94 \%$ in the corrosive process of ASTM 1020 carbon steel in $0.5 \mathrm{~mol} . \mathrm{L}^{-1} \mathrm{HCl}$ solution. These results corroborate the calculations obtained from the equivalent circuit.

SEM images showed that the inhibitors were adsorbed on the carbon steel surface, acting as a protective barrier against the evolution of the corrosive process on the substrate.

\section{Acknowledgements}

Authors would like to acknowledge to CAPES, CNPq, UESC and FAPESB for financial support; Óleos de Palma S/A company (BA, BR) for donations of materials for research, the BIOMA (Environment and Bioenergy Group) of State University of Santa Cruz (BA, BR) for FTIR analysis, LAMMA (Environment and Materials Laboratory) of State University of Santa Cruz (BA, BR) for support and CME (Electronic Microscopy Center) of State University of Santa Cruz (Ba, BR) for SEM images.

\section{References}

1. Sastri VS. Green Corrosion Inhibitors: theory and practice. Hoboken: Wiley; 2011.

2. NACE. International measures of prevention, applocation and economics of corrosion technology. Houston: NACE International; 2016.

3. Assad AM, Sarbini NN, Sulaiman A, Ismail M, Huseien GF, Majid ZA, et al. Improved corrosion resistance of mild steel against acid activation: impact of novel Elaeis guineensis and silver nanoparticles. J Ind Eng Chem. 2018;6:139-48.

4. Mobin M, Basik M, Aslam J. Boswellia serrata gum as highly efficient as sustainable corrosion inhibitor for low carbon steel in $1 \mathrm{M} \mathrm{HCl}$ solution: experimental and DFT studies. J Mol Liq. 2018;263:174-86.

5. Barreto LS, Tokumoto MS, Guedes IC, Melo HG, Amado FDR, Capelossi VR. Study and assessment of the efficiency of the Cocoa Bark extracted from the Theobroma Cacao as an inhibitor of the corrosion of carbon steel in substitution of benzotriazole. Mater Res. 2018;22(1):e20160309.

6. Alibakhshi E, Ramezanzadeh M, Bahlakeh G, Ramezanzadeh B, Mahdavian M, Motamedi M. Glucurrhiza glabra leaves extract as a green corrosion inhibitor for mild steel in $1 \mathrm{M}$ hydrochloric acid solution: Experimental, Mol. dynamic, Monte Carlo and quantum mechanics study. J Mol Liq. 2018;255:185-98.

7. Barreto LS, Tokumoto MS, Guedes IC, Melo HG, Amado FDR, Capelossi VR. Evaluation of the anticorrosion performance of peel garlic extract as corrosion inhibitor for ASTM 1020 carbon steel in acidic solution. Revista Matéria. 2017;22:11852.

8. Khadom AA, Abd AN, Ahmed NA. Xanthium strumarium leaves extracts as a friendly corrosion inhibitor of low carbon steel in hydrochloric acid: kinects and mathematical studies. Chem Eng J. 2018;25:13-21.

9. Santos AM, Almeida TF, Cotting F, Aoki IV, Melo HG, Capelossi VR. Evaluation of castor bark powder as a corrosion inhibitor for carbon steel in acidic media. Mater Res. 2017;20(Suppl. 2):492-505.

10. Hernandes IS, Cunha JN, Santana CA. Application of an aqueous extract of cotton seed as a corrosion inhibitor for mild steel in $\mathrm{HCl}$ media. Mater Res. 2021;24(1):1-10.

11. Begum AAL, Vahith RMA, Kotra V, Shaik MR, Abdelgawad A, Awwad EM, et al. Spilanthes acmella leaves extract for corrosion inhibition in acid medium. Coatings. 2021;11:106-29.

12. Odewunmi NA, Umoren S, Asem ZM. Watermelon waste products as green corrosion inhibitors for mild steel in $\mathrm{HCl}$ solution. J Environ Chem Eng. 2015;3(1):286-96.

13. Raja PB, Sethuraman MG. Natural products as corrosion inhibitor for metals in corrosive media. Mater Lett. 2008;62:113-6.

14. Satapathy AK, Gunasekaran G, Sahoo SC, Amit K, Rodrigues PV. Corrosion inhibition by Justicia gendarussa plant extract in hydrochloric acid solution. Corros Sci. 2009;51:2848-56.

15. Rocha JC, Gomes JACP. Natural corrosion inhibitors - proposal to obtain ecological products of low cost from industrial waste. Revista Matéria. 2017;22:1517-76.

16. Lecumberri E, Mateos R, Izquierdo-Pulido M, Rupérez P, Goya L, Bravo L. Dietary fibre composition, antioxidant capacity and physic-chemical properties of a fibre-rich product from cocoa (Theobroma cacoa L.). Food Chem. 2007;104(3):948-54.

17. Payne MJ, Hurst WJ, Stuart DA, Ou B, Fan E, Ji H, et al. Determination of total procyanidins in selected chocolate and confectionery products using DMAC. JAOAC Int. 2010;93(1):8996.

18. Smit HJ. Theobromine and the Pharmacology of Cocoa. In: Fredholm BB, editor. Handbook of Experimental Pharmacology - Methylxanthines. Oxford: Springer Berlin Heidelberg; 2011, p. 201-234.

19. Conti A, Bernardini V, Poli A, Paoletti R. Chocolate and Health: A Brief Review of the Evedence. In: Paoletti R, Poli A, Conti A, Visioli F, editors. Chocolate and Health. Milano: Springer Milan; 2012.

20. Martínez R, Torres P, Meneses MA, Figueroa JG, PérezÁlvarez JA, Viuda-Martos M. Chemical, technological and in vitro antioxidant properties of cocoa (Theabroma cacao L.) co-products. Food Res Int. 2012;49(1):39-45.

21. Fayomi OSI, Popoola API. The inhibitory effect and adsorption mechanism of roasted elaeis guineensis as green inhibitor on the corrosion process of extruded AA6063 Al-Mg-Si alloy in simulated solution. Silicon. 2014;6:137-43.

22. Nwigbo SC, Okafor VN, Okewale AO. Comparative study of Elaeis Guiniensis Exudates (Palm Wine) as a corrosion inhibitor for mild steel in acidic and basic solutions. Res J Appl Sci Eng Technol. 2012;4:1035-9. 
23. Wallace PA, Adu EK, Rhule SW. Optimal storage conditions for cocoa cake with shell, palm kernel cake and copra cake as poultry and livestock feed in Ghana. Livest Res Rural Dev. 2010;22(2).

24. Santos AM, Almeida TF, Cotting FI, Aoki V, Melo HG, Capelossi VR. Evaluation of palm kernel cake powder (Elaeis guineensis Jacq.) as corrosion inhibitor for carbon steel in acidic media. Met Mater Int. 2020;27:1519-30.

25. Dwivedi D, Lepková K, Becker T. Carbon steel corrosion: a review of key surface properties and characterization methods. RSC Advances. 2017;7(8):4580-610.

26. Valbon A, Neves M, Echevarria A. Anticorrosive effect of PVP 40000 against AISI 1020 carbon steel in $\mathrm{HCl}$. Mat Res. 2018;21(6):e20170847.

27. Verma KD, Khan F. Corrosion inhibition of mild steel in hydrochloric acid using extract of glycine max leaves. Res Chem Intermed. 2016;42:3489-506.

28. Alaneme KK, Daramola YS, Olusegun SJ, Afolabi AS. Corrosion inhibition and adsorption characteristics of rice husk extracts on mild steel immersed in 1M H2SO4 and $\mathrm{HCl}$ solutions. Int J Electrochem Sci. 2015;10:3553-67.

29. Torres AR, Cisneros MGV, Chavarín JU, Arteaga CC, Rodríguez MAV. The use of Brugmansia arborea as a green corrosion inhibitor for AISI 1018 carbon steel in acid media. Green Chem Lett Rev. 2021;14(1):108-18. http://dx.doi.org/10.1080/17518 253.2020.1862924.

30. Garai S, Jaisankar P, Singh JK, Elango A. A comprehensive study on crude methanolic extract of Artemisia pallens (Asteraceae) and its active component as effective corrosion inhibitors of mild steel in acid solution. Corros Sci. 2012;60:193-204.

31. Zucchi F, Omar IH. Studies on the inhibitive effect of Occimum viridis extract on the acid corrosion of mild steel. Surf Technol. 1985;24:391-9.

32. Prabakaran M, Kim S, Mugila N, Hemapriya H, Parameswari K, Chitra S, et al. Aster koraiensis as nontoxic corrosion inhibitor for mild steel in sulfuric acid. J Ind Eng Chem. 2017;52:235-42.

33. Li X, Deng S, Fu H. Inhibition of the corrosion of steel in $\mathrm{HCl}, \mathrm{H}_{2} \mathrm{SO}_{4}$ solutions by bamboo leaf extract. Corros Sci. 2012;62:163-75.

34. El-lateef HMA, Abbasov VM, Aliyeva LI, Qasimov EE, Ismayilov IT. Inhibition of carbon steel corrosion in $\mathrm{CO}_{2}-$ saturated brine using some newly surfactants based on palm oil: experimental and theoretical investigations. Mater Chem Phys. 2013;142:502-12.

35. Ji G, Dwivedi P, Sundaram S, Prakash R. Aqueous extract of Argemone mexicana roots for effective protection of mild steel in an $\mathrm{HCl}$ Environment. Res Chem Intermed. 2016;42:439-59.

36. Li XH, Deng SD, Fu H. Inhibition by Jasminum nudiflorum Lindl. leaves extract of the corrosion of cold rolled steel in hydrochloric acid solution. J Appl Electrochem. 2010;40:1641-9.

37. Zoltowski P. On the electrical capacitance of interfaces exhibiting constant phase element behaviour. J Electroanal Chem. 1998;443:149.

38. Rodríguez-Torres A, Valladares-Cisneros MG, GonzalesRodríguez JG. Use of Salvia officinalis as green corrosion inhibitor for carbon steel in acidic media. Int J Electrochem Sci. 2015;10:4053-67.

39. Ghazouani T, Hmamou DB, Meddeb E, Salghi R, Benali O, Bouya $\mathrm{H}$, et al. Antioxidant activity and effect of quince pulp extract on the corrosion of C-steel in $1 \mathrm{M} \mathrm{HCl}$. Res Chem Intermed. 2015;41:7463-80.

40. Marzorati S, Verotta L, Trasatti SP. Green corrosion inhibitors from natural sources and biomass wastes. Molecules. 2018;24(1):48.

41. Rani ABE, Bas BBJ. Green inhibitors for corrosion protection of metals and alloys: an overview. Int J Corros. 2012;12:1-15.
42. Hassannejad H, Nouri A. Sunflower seed hull extract as a novel green corrosion inhibitor for mild steel in $\mathrm{HCl}$ solution. J Mol Liq. 2018;254:377-82.

43. Souza TF, Magalhães M, Torres VV, D'elia E. Inhibitory action of Ilex paraguariensis extracts on the corrosion of carbon steel in $\mathrm{HCl}$ solution. Int J Electrochem Sci. 2015;10:22-33.

44. Liao LL, Mo S, Luo HQ, Li NB. Longan seed and peel as environmentally friendly corrosion inhibitor for mild steel in acid solution: experimental and theoretical studies. J Colloid Interface Sci. 2017;499:110-9.

45. Khadom AA, Abd AN, Ahmed NA. Xanthium strumarium leaves extracts as a friendly corrosion inhibitor of low carbon steel in hydrochloric acid: kinects and mathematical studies. Chem Eng J. 2018;25:13-21.

46. Boumhara K, Tabyaoui M, Jama C, Bentiss F. Artemisia mesatlantica essential oil as green inhibitor for carbon steel corrosion in $1 \mathrm{M} \mathrm{HCl}$ solution: ElectroChem. and XPS investigations. J Ind Eng Chem. 2015;29:146-55.

47. Hernandes IS, Cunha JN, Santana CA. Application of an aqueous extract of cotton seed as a corrosion inhibitor for mild steel in HCl media. Mater Res. 2021;24(1):1-10.

48. Begum AAL, Vahith RMA, Kotra V, Shaik MR, Abdelgawad A, Awwad EM, et al. Spilanthes acmella leaves extract for corrosion inhibition in acid medium. Coatings. 2021;11:106-29.

49. Boumhara K, Tabyaoui M, Jama C, Bentiss F. Artemisia mesatlantica essential oil as green inhibitor for carbon steel corrosion in $1 \mathrm{M} \mathrm{HCl}$ solution: electrochemical and XPS investigations. J Ind Eng Chem. 2015;29:146-55.

50. Assad AM, Sarbini NN, Sulaiman A, Ismail M, Huseien GF, Majid ZA, et al. Improved corrosion resistance of mild steel against acid activation: impact b.of novel Elaeis guineensis and silver nanoparticles. J Ind Eng Chem. 2018;63:139-48.

51. Uhlig HH. Corrosion and corrosion control. 2nd ed. New York: John Wiley \& Sons; 1971.

52. Khadom AA, Abd AN, Ahmed NA. Xanthium strumarium leaves extracts as a friendly corrosion inhibitor of low carbon steel in hydrochloric acid: kinects and mathematical studies. Chem Eng J. 2018;1:13-21.

53. Prabakaran M, Kim SH, Hemapriya V, Chung IM. Tragia plukenetii extract as an eco-friendly inhibitor for mild steel corrosion in $\mathrm{HCl} 1 \mathrm{M}$ acidic medium. Res Chem Intermed. 2016;42:3703-19.

54. Mobin M, Rizvi M. Inhibitory effect of xanthan gum and sunergistic surfactant additivies for mild steel corrosion in 1 M HCl. Carbohydr Polym. 2016;136:384-93.

55. Khadom AA, Abd AN, Ahmed NA. Xanthium strumarium leaves extracts as a friendly corrosion inhibitor of low carbon steel in hydrochloric acid: kinects and mathematical studies. Chem Eng J. 2018;25:13-21.

56. Begum AAL, Vahith RMA, Kotra V, Shaik MR, Abdelgawad A, Awwad EM, et al. Spilanthes acmella leaves extract for corrosion inhibition in acid medium. Coatings. 2021;11:106-29.

57. Silveira PTS, Melo LJP, Souza LS, Bispo ES, Soares SE. Protease prospecion and determination of its isoenzymes activity in cocoa cultivars (Theobroma cacao L.). Food Sci Technol. 2017;37(3):369-77.

58. ICCO: International Cocoa Organization. Quarterly Bulletin of Cocoa Statistics. Abidjan: ICCO; 2019. Available from: https:// www.icco.org/quarterly-bulletin-of-cocoa-statistics-november-2019/

59. Mororó RC. Aproveitamento de derivados, subprodutos e resíduos do cacau. In: Valle, R. R., editor. Ciência, tecnologia e manejo do cacaueiro. Ilhéus: Ceplac; 2007. p. 371- 421.

60. Morais JPS, Medeiros EP, Silva JA, Rosa MF, Souza MMS Fo, Alexandre LC, et al. Valorização de Co-produtos da Cadeia do Dendê. Fortaleza: Embrapa Agroindústria Tropical; 2013.

61. Choong CG, Mckay A. Sustainability in the Malaysian palm oil industry. J Clean Prod. 2014;85:258-64. 
62. Arlorio M, Coïsson JD, Travaglia F, Varsaldi F, Miglio G, Lombardi G, et al. Antioxidant and biological activity of phenolic pigments from Theobroma cacao hulls extracted with supercritical CO2. Food Res Int. 2005;38(8-9):1009-14.

63. Miralrio A, Espinoza VázquezA. Plant extracts as green corrosion inhibitors for different metal surfaces and corrosive media: a review. Processes. 2020;8(8):942. http://dx.doi.org/10.3390/pr8080942.
64. Erna M, Herdini H, Futra D. Corrosion inhibition mechanism of mild steel by amylose-acetate/carboxymethyl chitosan composites in acidic media. Int J Chem Eng. 2019;2019:8514132. http:// dx.doi.org/10.1155/2019/8514132.

65. Verma DK, Khan F. Corrosion inhibition of mild steel in hydrochloric acid using extract of glycine max leaves. Res Chem Intermed. 2015;42(4):3489-506. http://dx.doi.org/10.1007/s11164-015-2227-7. 